\title{
IMPLEMENTASI APLIKASI KAHOOT SEBAGAI MEDIA PEMBELAJARAN BERBASIS GAME DALAM PELAJARAN PENDIDIKAN AGAMA KATOLIK
}

\author{
Natalis Sukma Permana \\ STKIP Widya Yuwana \\ natalisukma@widyayuwana.ac.id
}

\begin{abstract}
In the world of education, learning media has a very important role. The position of learning media as a tool or means of conveying messages from teachers to students. In learning activities, the media has the function of attention, cognitive function, afective function and compensatory function. One of the media learning that can be used is the Kahoot application. Media learning in the form of visuals has the benefit of being able to attract students' attention and motivate students to learn. Kahoot is a game-based visual media that is easily accessed and used by teachers and students. Game-based learning media is favored by the digital generation. Kahoot can be used as a teaching medium for Catholic religion education. In its utilization, it can be used for brainstorming, pretest-posttest, to find out understanding regarding the presented subject matter.
\end{abstract}

Keywords: Game Based Learning, Catholic Religius Education, Kahoot Media

\section{PENDAHULUAN}

Keberhasilan dalam sebuah proses pembelajaran dapat dinilai dari kemampuan peserta didik dalam memahami konsep-konsep materi dan dari evaluasi hasil belajar. Salah satu faktor penentu keberhasilan pembelajaran adalah penggunaan strategi, model, dan media pembelajaran. Pemilihan model pembelajaran dapat membantu mendapatkan informasi, ide, keterampilan, dan cara berpikir (Suprijono, 2011:46). Selain pemilihan model pembelajaran, media pembelajaran yang digunakan dalam proses pembelajaran dapat memperjelas informasi, memusatkan perhatian siswa, meningkatkan motivasi belajar dan mendorong prestasi belajar (Arsyad, 2014:3). Media pembelajaran merupakan bagian penting dari proses pembelajaran. Media yang baik akan diharapkan mampu mendukung variasi pembelajaran. Media pembelajaran adalah sarana atau alat bantu yang digunakan dalam pembelajaran untuk menyampaikan pesan dari guru kepada peserta didik (Suryani, dkk. 2018:4). 
Saat ini, kita telah memasuki revolusi industri 4.0, yakni era dimana dunia teknolgi masuk dalam dunia pendidikan. Pada akhirnya, situasi seperti ini menuntut kemampuan guru untuk beradaptasi, menguasai dan memiliki kompetensi dalam menggunakan alat-alat teknologi guna mendukung proses pembelajaran. Teknologi digital diharapkan dapat dimanfaatkan untuk meningkatkan mutu pembelajaran, dengan memanfaatkan teknologi digital diharapkan dapat menarik dan meningkatkan motivasi belajar peserta didik dalam pembelajaran. Oleh karena itu, guru diharapkan kreatif dalam melaksanakan proses pembelajaran. Kendala yang mungkin dihadapi saat pembelajaran adalah keterbatasan guru dalam menguasi perangkat atau aplikasi pendukung kegiatan pembelajaran, peserta didik yang tidak aktif dalam proses pembelajaran, dan timbulnya rasa bosan dalam kegiatan pembelajaran. Dalam proses pembelajaran Pendidikan Agama Katolik hal-hal itu juga mungkin terjadi. Dalam kegiatan pembelajaran, hendaknya guru juga dapat memperhatikan karakteristik peserta didik dan minat belajar yang disukai di era digital. Inilah yang mendukung penulis untuk mencoba merumuskan sebuah desain pembelajaran dengan menggunakan media pembelajaran berbasis digital.

Ada beberapa aplikasi online yang bisa dimanfaatkan sebagai media pembelajaran, salah satunya adalah Kahoot. Kahoot merupakan salah satu media pembelajaran interaktif berbasis game yang mudah diakses dan user friendly. Kahoot merupakan salah satu media pembelajaran yang dapat digunakan untuk mengembangkan kuis seperti kegiatan pre test atau post test, atau soal-soal yang harus dipecahkan. Kahoot memuat fitur kuis, game, diskusi, dan survei. Game dan diskusi dapat dimainkan secara individu atau kelompok. Dengan menggunakan aplikasi Kahoot diharapkan dapat meningkatakn interaktifitas dalam proses pembelajaran, sehingga tercipta proses pembelajaran yang menarik, menyenangkan dan tidak membosankan saat proses pembelajaran. Aplikasi ini sangat cocok untuk generasi digital yang menyukai tampilan dan fitur-fitur yang cukup menarik, sehingga diharapkan dapat mendukung proses belajar mengajar pelajaran Pendidikan Agama Katolik mulai dari jenjang Sekolah Dasar sampai Sekolah Menegah Atas.

\section{PEMBAHASAN}

\subsection{Pengertian Media Pembelajaran}

Media berasal dari bahasa latin “medius” yang berarti tengah, perantara atau pengantar. Media merupakan segala sesuatu yang dapat menyampaikan dan menyalurkan pesan sehingga tercipta lingkungan belajar yang kondusif dan dapat melakukan proses belajar secara efisien dan efektif (Munadi, 2012:8). Media pembelajaran seharusnya menjadi bagian yang tidak dipisahkan dalam kegiatan pembelajaran baik secara online ataupun offline. 
Menurut Gagne (Arsyad, 2002:4), media pembelajaran adalah komponen dalam lingkungan belajar yang dapat merangsang mereka untuk belajar. Senada dengan hal itu, Brigss (Arsyad, 2002:3) juga mengartikan media sebagai alat untuk memberikan rangsangan bagi peserta didik agar terjadi proses belajar. Pada hakikatnya, belajar mengajar adalah proses komunikasi, sehingga media yang digunakan dalam proses tersebut disebut sebagai media pembelajaran. Disinilah peran media pembelajaran untuk menyampaikan pesan pembelajaran. Dalam proses pembelajaran, media memiliki beberapa fungsi, yakni fungsi yang pertama adalah untuk menarik perhatian. Kedua, fungsi afektif, yaitu media visual dapat menggugah emosi peserta didik. Ketiga, fungsi kognitif untuk memperlancar atau memperjelas tujuan pembelajaran dan memberikan informasi. Keempat, fungsi kompensatoris, yaitu media memfasilitasi peserta didik yang memilki kemampuan lemah dan cukup tinggi sehingga membantu peserta didik untuk memahami.

\subsection{Kahoot Sebagai Media Pembelajaran berbasis Game}

Game based learning merupakan suatu alternatif yang dapat meningkatkan keikutsertaan peserta didik dalam proses pembelajaran. Aplikasi Kahoot merupakan salah satu platform pembelajaran yang mengkombinasikan evaluasi pembelajaran dengan game interaktif. Kahoot adalah aplikasi pembelajaran yang dikembangkan dari hasil kolaborasi University of Technology and Science oleh Johan Brand, Jamie Booker, dan Mortwn Versvik. Kahoot dikembangkan dengan website sederhana dan menarik secara online (Christiani, Adrianto, Anggraini, 2019:5).

Kahoot merupkan media pembelajaran yang menjalankan fungsi atensi, karena menarik perhatian, memusatkan perhatian untuk berkonsentrasi pada kegiatan pembelajaran. Kahoot merupakan salah satu media pembelajaran visual, dan media visual sat ini sangat digemari oleh generasi digital. Kahoot bisa memenuhi gaya belajar generasi digital (Mustikawati, 2019:101).

Sebagai sebuah platform pembelajaran berbasis game, Kahoot dapat dikatakan sebagai media pembelajaran yang menghibur untuk mencapai sebuah tujuan pembelajaran. Game merupakan sebuah aktifitas terstruktur atau semi terstruktur yang bertujuan untuk hiburan atau dapat digunakan sebagai sarana pendidikan. Karakteristik game yang menyenangkan sangat digemari banyak orang, terutama para peserta didik saat ini yang notabenenya adalah generasi digital (Wahono, 2007).

Game sebagai sebuah trend pembelajaran yang dijadikan literasi baru dalam kegiatan pembelajaran atau bisa dikatakan sebagai sebuah potential learning environment. Jadi, Kahoot dapat dikatakan sebagai sebuah media pembelajaran berbasis game yang dapat menyampaikan pesan pembelajaran dan 
dapat dijadikan sebagai sebuah wahana penghubung, sehingga pesan yang disampaikan dapat tersampaikan dengan baik kepada si penerima pesan.

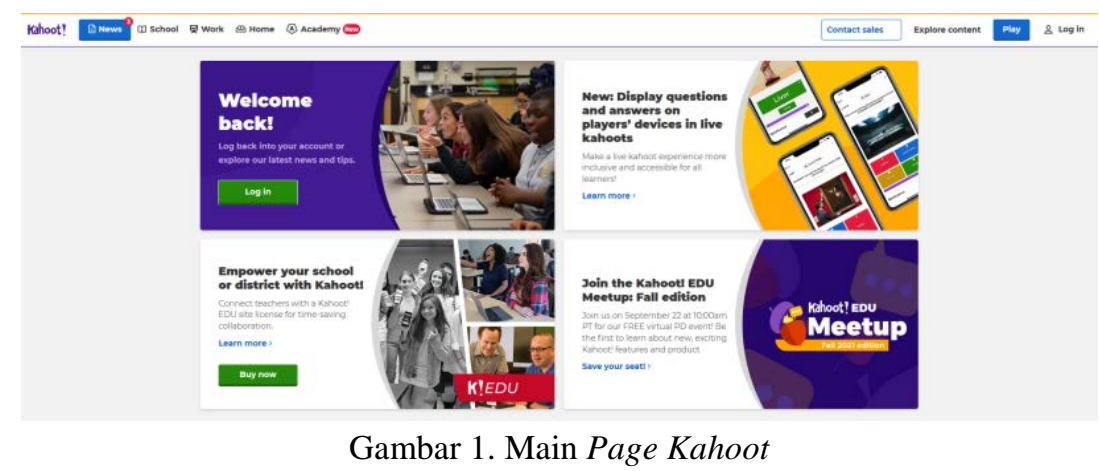

\subsection{Manfaat Kahoot dalam Kegiatan Pembelajaran}

Sebagai sebuah media pembelajaran digital, Kahoot memiliki beberapa kelebihan, antara lain: (1) Kahoot dapat merangsang minat peserta didik. Kahoot dapat membantu meningkatkan minat peserta didik untuk menjawab atau mengerjakan games yang diberikan oleh guru. Peserta didik dapat berlombalomba untuk memenangkan atau mendapatkan skor yang tertinggi sehingga memacu peserta didik untuk terus belajar; (2) Kahoot untuk memantau minat peserta didik. Dengan menggunakan aplikasi Kahoot seorang guru dapat memantau kekuatan dan kelemahan peserta didik dalam menguasai materi. Penguasaan materi dapat dilihat dari jumlah jawaban benar yang dijawab oleh peserta didik saat pelajaran berlangsung. Dengan demikian guru juga tertantang untuk mengulang kembali materi yang belum dikuasi oleh peserta didik; dan (3) Kegiatan pembelajaran menjadi lebih menarik. Dengan pembelajaran berbasis game dapat merangsang dan meningkatkan minat peserta didik dan melihat reaksi peserta didik terhadap penjelasan yang diberikan oleh guru.

\subsection{Kelebihan dan Kekurangan Pemanfaatan Kahoot dalam Pembelajaran}

Sebagai sebuah aplikasi pembelajaran yang dapat diakses secara gratis dan sangat user friendly, kehadiran Kahoot dalam dunia pendidikan sangat membantu para guru dalam membuat variasi pembelajaran. Februari 2019, similarweb melakukan sebuah riset dan mencatat 34 juta pengguna aplikasi ini, hal tersebut membuat Kahoot sebagai media game base learning yang sangat digemari oleh para penggunanya (Putri \& Muzakie, 2019:221).

Kahoot dapat dimanfaatkan dengan mudah, pengguna Kahoot tidak perlu menginstal aplikasi Kahoot dalam smartphone, PC, atau laptop karena dikembangkan melalui web base software. Sebagai pengguna, peserta didik tinggal mengakses kahoot.it dan mendapatkan PIN yang tertera di layar smartphone, PC atau laptop yang digunakan. Guru pun dapat dengan mudah 
mengedit soal-soal yang diberikan dari smartphone tanpa harus menggunakan perangkat komputer dan bisa dilakukan dimana saja. Selain itu, guru akan sangat terbantu untuk membuat feedback dari hasil belajar siswa. Namun Kahoot juga memiliki kekurangan dari beberapa sisi, yaitu perlu jaringan internet yang cukup baik ketika mengakses aplikasi ini, selain itu juga membutuhkan perangkat lain seperti LCD proyektor dan laptop. Selanjutnya, juga perlu didukung dengan kemampuan para guru untuk beradaptasi dengan teknologi.

\subsection{Pemanfaatan Kahoot dalam Pembelajaran Pendidikan Agama Katolik (PAK)}

Kahoot adalah salah satu media pembelajaran interaktif yang dapat digunakan dalam kegiatan pembelajaran. Kahoot ditampilkan dalam bentuk game online yang berbentuk kuis. Dalam hal ini, penulis berpandangan bahwa Kahoot merupakan salah satu game yang edukatif. Game edukasi adalah sebuah media pembelajaran yang dapat merangsang minat belajar sambil bermain (Hartanti, 2019:79).

Untuk mengakses Kahoot, yang harus dilakukan pertama kali adalah login dengan menggunakan email. Kahoot memiliki dua alamat website, yaitu https://kahoot.com untuk pendidik dan https://kahoot.it untuk peserta didik. Kahoot adalah platform yang seluruh fiturnya dapat digunakan secara gratis. Kahoot memiliki kelebihan, salah satunya dapat dimainkan secara berkelompok ataupun individu. Proses evaluasi dari kegiatan belajar dapat dielaborasikan dengan bahan lainnya dari internet.

Peralatan yang perlu dipersiapkan oleh guru untuk menggunakan Kahoot, meliputi: (a) LCD Proyektor; (b) Jaringan internet yang cukup baik; (c). Peserta didik membawa smartphone, tablet atau laptop. Setelah menyiapkan beberapa peralatan tersebut, langkah selanjutnya adalah membuat kuis atau evaluasi pembelajarannya. Tahap-tahap yang perlu dipersiapkan: (1) Ketik kahoot.com dan login dengan email yang terdaftar di akun Kahoot. Jika belum memiliki akun Kahoot dapat sign up for free dan menggunakan akun gmail; (2) Buka Kahoot sesuai dengan yang diinginkan, klik quiz untuk membuat kuis yang diinginkan dalam bentuk multiple coice atau true and false; (3) Setiap pertanyaan dapat di setting lamanya waktu menjawab, guru bisa menyesuaikan dengan tingkat kesulitan soal; (4) Setiap akhir soal di Kahoot dapat ditambahkan gambar untuk menarik perhatian atau memperjelas pesan yang ingin disampaikan; (5) Setelah selesai membuat pesan, langkah akhir yang dapat dilakukan adalah copy paste link atau membagikan PIN kepada peserta didik. 


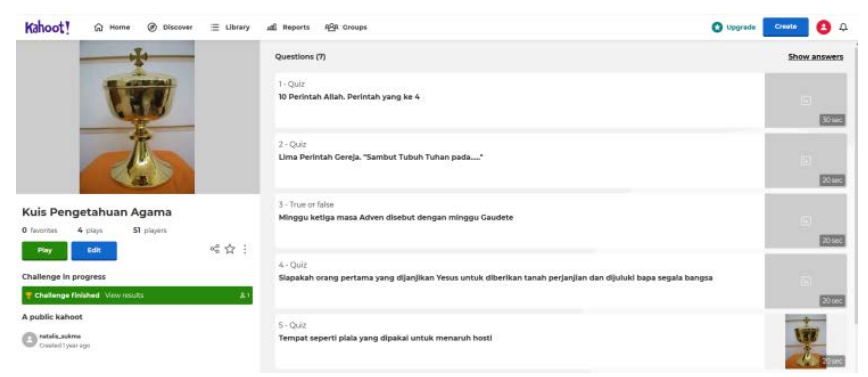

Gambar 2. Tampilan Kuis di dalam Kahoot

Untuk peserta didik tidak perlu mendaftar, akun juga sama seperti saat guru join ke Kahoot. Untuk menjawab kuis di Kahoot, peserta didik tinggal mendapatkan link atau PIN dari guru dengan menerapkan beberapa langkah, meliputi: (1) Mengakses alamat web Kahoot.it; (2) Peserta didik dapat join ke Kahoot dengan PIN yang muncul di layar. Setelah itu peserta didik dapat menuliskan nama panggilan atau nama tim jika akan dimainkan secara tim (dengan menggunakan mode group); (3) Nama peserta didik akan muncul di layar monitor, setelah lengkap nama peserta didiknya, guru dapat memulai menjalankan kuis.

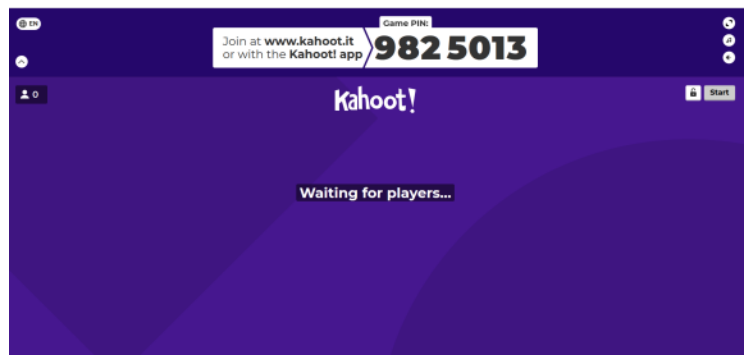

Gambar 3. Tampilan PIN Kahoot

Penggunaan aplikasi Kahoot dalam pelajaran Pendidikan Agama Katolik diharapkan dapat memotivasi peserta didik dalam belajar. Para guru juga dapat memanfaatkan fitur-fitur yang ada di dalam Kahoot, seperti menarik perhatian peserta didik pada awal kegiatan pembelajaran atau di akhir sebagai evaluasi kegiatan pembelajaran.

Di awal pembelajaran seorang guru dapat memanfaatkan fitur brain storming untuk mengingat kembali materi pelajaran agama di minggu sebelumnya atau untuk menguji pengetahuan peserta didik terkait materi yang sedang dipelajari saat itu. Seorang guru dapat secara kreatif mendesain kegiatan pembelajaran, misalnya peserta didik diminta untuk menuliskan ide mereka atau memilih topik yang paling diminati untuk dipelajari. Fitur lain yang dapat dimanfaatkan untuk kegiatan evaluasi pembelajaran adalah kuis dalam bentuk multiple choice, true and false atau type answer, kuis yuang dibuat juga bisa dilengkapi dengan gambar sehingga dari segi tampilan cukup menarik perhatian. 
Peserta didik akan merasa tertantang jika dalam pelajaran agama didesain semacam kompetisi dalam bermain game, hal ini berarti aplikasi Kahoot dapat memotivasi peserta didik untuk mempelajarai materi-materi yang diajarkan sehingga peserta didik terpacu untuk mendapatkan nilai tertinggi. Berikut ini contoh tampilan beberapa tahapan pembuatan kuis Kahoot dalam pelajaran Pendidikan Agama Katolik.

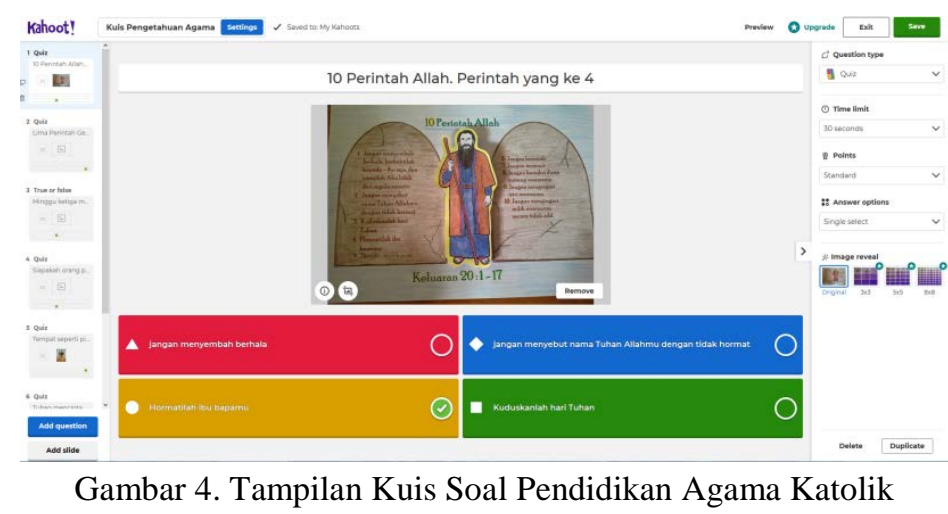

\section{KESIMPULAN}

Pada hakekatnya belajar merupakan sebuah proses komunikasi dua arah. Dalam berkomunikasi memerlukan media sebagai sarana penyampai pesan. Media pembelajaran adalah sarana atau alat yang digunakan dalam proses pembelajaran untuk membantu menyampaikan pesan-pesan pembelajaran. Kahoot merupakan salah satu media pembelajaran digital berbasis game yang dapat dioptimalkan untuk memusatkan perhatian dan memberikan evaluasi pembelajaran. Dalam pembelajaran Pendidikan Agama Katolik, konten-konten pembelajaran dapat diaplikasiaskan melalui Kahoot. Soal-soal dalam bentuk games atau kuis dapat dikembangkan sesuai dengan jenjang pendidikan dan materi yang dipelajari. Untuk menarik kegiatan pembelajaran Pendidikan Agama Katolik Kahoot dapat dimanfaatkan untuk brain storming, pre test atau post test. Dalam pemanfaatan aplikasi ini perlu didukung dengan sarana yang memadahi dan keterampilan guru dalam menggunakan teknologi digital.

\section{DAFTAR PUSTAKA}

Arsyad, Azhar., 2014, Media Pembelajaran. Jakarta: PT Rajagrafindo Persada. Arsyad, Azhar. 2002. Media Pembelajaran, edisi 1. Jakarta: PT. Raja Grafindo Persada.

Christiani, Natalia,. Adrianto, Hebert., Anggraini, Lya Dewi., 2019, Modul Teknologi Pembelajaran KAHOOT. CV Jejak, anggota IKAPI. Sukabumi. Jawa Barat. 
Hartanti, Dwi, 2019, "Meningkatkan motivasi belajar siswa dengan media pembelajaran interaktif game kahoot berbasis hypermedia", dalam prosiding seminar nasional Kebijakan dan pengembangan pendidikan di era revolusi industri 4.0”, Hal 78-85, Diunduh di https://jurnal.ustjogja.ac.id/index.php/snpep2019/article/view/5631.

Munadi., 2008, Media Pembelajaran Sebuah Pendekatan Baru. Jakarta: Gaung Persada Perss.

Mustikawai, Fenny Eka., 2019, "Fungsi Aplikasi Kahoot Sebagai media pembelajaran bahasa Indonesia", dalam Prosiding Bulan Bahasa, Hal 99104.

Putri, A. R., \& Muzakki, M. A, 2019, "Implemetasi Kahoot sebagai Media Pembelajaran Berbasis Digital Game Based Learning dalam Mengahadapi Era Revolusi Industri 4.0”, Prosiding Seminar Nasional Universitas Muria Kudus,1-7, Diunduh di http://pgsd.umk.ac.id/files/prosiding/2019/27__Aprilia_Riyana.pdf.

Suprijono, Agus., 2011, Model-Model Pembelajaran. Jakarta: Gramedia Pustaka Jaya.

Suryani, N., Setiawan, A., Putria, A., 2018, Metode Pembelajaran Inovatif dan Pengembangannya. Bandung: Rosda Karya.

Wahono, Romi Satria., 2007, "Sistem eLearning Berbasis Model Motivasi Komunitas", dalam Jurnal Teknodik No. 21/XI/Teknodik/Agustus/2007. 